\title{
The Study was Conducted Using Isobaric 0.75\% Ropivacaine 3.5ml (26.25mg) Intrathecally for Lower Limb Surgeries to Evaluate Onset and Duration of Sensory Block \& Onset and Duration of Motor Block
}

\author{
Monika Saini ${ }^{1}$, Nagesh Mudgal $^{2}$, Smita Engineer ${ }^{3}$ \\ ${ }^{1}$ Assistant Professor, Department of Anaesthesiology, Index Medical College Hospital \& Research Centre, Indore, ${ }^{2}$ Senior Resident, Department of Anaesthesiology, Index \\ Medical College Hospital \& Research Centre, Indore, ${ }^{3}$ Associate Professor, Department of Anaesthesiology, BJMC, Ahmedabad.
}

\section{Abstract}

Background: This study was conducted at Civil Hospital, BJ Medical College, Ahmedabad, after approval from the ethical committee. Fifty patients admitted in our hospital undergoing lower extremity surgeries under spinal anaesthesia were included in the study. Subjects and Methods: Patients in the age group $18-60$ years were selected including 45 males and 5 females. 39 patients had a ASA grade I and 11 patients had ASA grade II. Various lower limb and orthopaedic surgeries like arthroscopic ligaments repair, tibial and flap surgeries were included. Result: The duration of surgeries ranged from 45 to 270 minutes. 2\% (1 patient) attained a maximum level of T4, 22\% (11 patients) had a maximum level of T6 , 26\% (13 patients ) had a maximum level of T8. Maximum number of patients, $44 \%$ (20 patients) had a level of T10. 6\% (3 patients) had attained a maximum level of T12. Three patients did not achieve complete motor level.By the end of 15 minutes, $86 \%$ ( 43) patients had achieved a complete motor block.By the end of 20 minutes 94\% (47) patients had attained a complete motor block. The mean time for complete motor block was 10.59 minutes (S.D. \pm 4.7$)$. Conclusion: A study was conducted in 50 patients belonging to ASA grade I and II posted for lower limb surgeries. They received 3.5ml of $0.75 \%$ isobaric Ropivacaine in L2-3 interspace. All patients were preloaded with $1000 \mathrm{ml}$ of ringer lactate. Following institution of subarachoid block sensory characteristics such as onset of sensory block, maximum level achieved, duration of sensory block and request for first dose of rescue analgesics were studied. Motor blockade characteristics such as onset of motor block, duration and quality of motor blockade were studied. Onset of sensory block till T10 level was found to be 8.5 minutes with a complete regression in 229.28minutes.

Keywords: Ropivacaine, Intrathecally, Lower Limb \& Surgeries.

Corresponding Author: Dr. Nagesh Mudgal, Senior Resident, Department of Anaesthesiology, Index Medical College Hospital \& Research Centre, Indore.

Received: June 2019

Accepted: June 2019

\section{Introduction}

Ropivacaine, the S-(-)-enantiomer of 1-propyl-2,6-pipecoloxylidide, is a new amino-amide local anaesthetic structurally related to bupivacaine and mepivacaine. ${ }^{[1]}$ Ropivacaine and levobupivacaine are newer, long- acting local anaesthetics which have been developed as an alternative to bupivacaine after reports of seizures and cardiac arrest. ${ }^{[2]}$

Quinke in 1891 demonstrated a safe, predictable means of performing lumbar puncture. History of local anaesthesia begins with use of cocaine an ester derivative in 1899 by August Bier in order to produce operative anaesthesia in six patients, the first real spinal anaesthesia. That was associated with several side effects like nausea, vomiting, headache, restlessness and excitability. ${ }^{[3]}$ Soon in 1905, Heimrich Braun, reported the use of procaine for operative spinal anaesthesia.

Lidocaine was first used in 1945. It has quick onset with duration lasting 30-90 minutes. Lidocaine has been used for short to intermediate length surgeries. It was associated with transient neurologic symptoms (TNS), which presents as low back pain and lower extremity dysesthesias with radiation to the buttocks, thighs, and lower limbs. ${ }^{[4,5]}$

\section{Subjects and Methods}

This study was conducted at Civil Hospital, BJ Medical College, Ahmedabad from March 2012 to Feb 2013, after approval from the ethical committee. Fifty patients admitted in our hospital undergoing lower extremity surgeries under spinal anaesthesia were included in the study.

\section{Inclusion Criteria}

- Age- 18-60 years

- ASA Grade - I and II

- Lower limb surgeries

- Valid informed consent

Exclusion Criteria

- Hematologic disease

- Bleeding and coagulation abnormalities

- Cardiac and respiratory diseases

- History of allergy to local anesthetics

- $\quad$ Pregnancy, paediatric age group, geriatric age group

- Local infection in lumbar region 
Pre-anesthetic assessment was done prior to the day of surgery which included past history of chronic illness and medication, drug therapy (especially corticosteroids, antihypertensive, anti-coagulant, anti-diabetic, anti convulsant medications), drug sensitivity and past anesthetic experience along with routine investigations including, haemoglobin, random blood sugar, serum urea, serum creatinine, and serum electrolytes, chest X-ray, ECG.

Informed and written consent was obtained after explaining the procedure to the patients. A thorough general, airway and physical examination of all systems was carried out. The nature of study and the procedure were explained to the patients, informed and written consent was taken.

\section{Results}

The study population consisted of 50 patients posted for lower limb orthopaedic and plastic surgeries. They received isobaric $0.75 \%$ ropivacine $3.5 \mathrm{cc}(26.25 \mathrm{mg})$ in L2-L3 interspace.

Table 1: Demographic data
\begin{tabular}{|l|l|}
\hline Parameters & $\begin{array}{l}\text { No. of patients } \\
\text { n= 50 (100\%) }\end{array}$ \\
\hline Age (mean) & $18-60(34.52)$ \\
\hline Sex (M:F) & $45: 5 \quad(90: 10)$ \\
\hline ASA Grade (I:II) & $39: 11(78: 22)$ \\
\hline Arthroscopic ligament repair & 12 \\
\hline Tibial surgeries & 8 \\
\hline Flap surgeries & 12 \\
\hline Others & 18 \\
\hline Duration of surgery (in mins) & $45-270(114.66$ mins) \\
& (S.D. 49.33) \\
\hline
\end{tabular}

Patients in the age group $18-60$ years were selected including 45 males and 5 females. 39 patients had a ASA grade I and 11 patients had ASA grade II. Various lower limb and orthopaedic surgeries like arthroscopic ligaments repair, tibial and flap surgeries were included. The duration of surgeries ranged from 45 to 270 minutes.

Table 2: Maximum height of sensory block.

\begin{tabular}{|l|l|l|}
\hline Level of block & No. of patients $(\mathbf{n = 5 0})$ & \% of patients \\
\hline T4 & 1 & 2 \\
\hline T6 & 11 & 22 \\
\hline T8 & 13 & 26 \\
\hline T10 & 22 & 44 \\
\hline T12 & 3 & 6 \\
\hline
\end{tabular}

\begin{tabular}{|l|l|l|}
\hline Table 3: Onset of complete motor block \\
\hline Time( in mins) & $\begin{array}{l}\text { No. of patients } \\
(\mathbf{n = 5 0})\end{array}$ & \% of patients \\
\hline $0-5$ & 7 & 14 \\
\hline $6-10$ & 26 & 52 \\
\hline $11-15$ & 9 & 18 \\
\hline $16-20$ & 4 & 8 \\
\hline $21-25$ & 1 & 2 \\
\hline
\end{tabular}

2\% (1 patient) attained a maximum level of T4, 22\% (11 patients) had a maximum level of T6, 26\% (13 patients) had a maximum level of T8. Maximum number of patients, $44 \%$ (20 patients) had a level of T10. 6\% (3 patients) had attained a maximum level of T12.
Three patients did not achieve complete motor level. By the end of 15 minutes, $86 \%$ (43) patients had achieved a complete motor block. By the end of 20 minutes $94 \%$ (47) patients had attained a complete motor block. The mean time for complete motor block was 10.59 minutes (S.D. \pm 4.7 ).

Table 4: Duration of sensory block

Table 4: Duration of sensory block
\begin{tabular}{|l|l|l|}
\hline Time( in mins) & No. of patients & \% of patients \\
\hline $120-150$ & 4 & 8 \\
\hline $151-180$ & 12 & 24 \\
\hline $181-210$ & 8 & 16 \\
\hline $211-240$ & 11 & 22 \\
\hline $241-270$ & 5 & 10 \\
\hline $271-300$ & 6 & 12 \\
\hline $301-330$ & 2 & 4 \\
\hline $331-360$ & 2 & 4 \\
\hline
\end{tabular}

Sensory block persisted for 2 hours in all patients. By 3 hours, $32 \%$ of patients had recovered from motor block. By 4 hours, $69 \%$ of patients had complete regression of sensory blockade. By 5 hours, $96 \%$ of patients had complete regression of sensory blockade. The mean duration of sensory block was $229.28 \pm 54.91$ minutes.

Table 5: Duration of motor block

\begin{tabular}{|l|l|l|}
\hline Time (in mins) & No. of patients & \% of patients \\
\hline $120-150$ & 13 & 26 \\
\hline $150-180$ & 11 & 22 \\
\hline $181-210$ & 10 & 20 \\
\hline $211-240$ & 8 & 16 \\
\hline $241-270$ & 4 & 8 \\
\hline $271-300$ & 4 & 8 \\
\hline
\end{tabular}

Motor block persisted for 2 hours in all the patients. By 3 hours, $47 \%$ patients had recovered from motor block. By 4 hours, $84 \%$ patients had complete regression of motor blockade. The mean duration of motor block was 200.61 \pm 56.79 mnutes.

\section{Discussion}

Van Kleef et al in their comparative study on isobaric $0.5 \%$ and $0.75 \%$ ropivacaine for lower limb surgeries observed that the median time to reach the highest level of analgesia was $15 \mathrm{mins}$ in $0.5 \%$ and $18.8 \mathrm{mins}$ in $0.75 \%$ group. The upper level of analgesia was T11 in 0.5\% group and T10-T11 in $0.75 \%$ group. Both were not significant. The analgesic spread was extremely variable with both the solutions being restricted to the lumbosacral segments or extending to the upper thoracic segments which suggests that the dose of glucose free ropivacaine has no effect on the spread of analgesia. ${ }^{[6]}$

Jean Marc Malinosky et al in the comparative study of isobaric ropivacine versus isobaric Bupivacaine for TURP the onset of anesthesia at T10 in study was $13 \pm 8$ mins to pinprick, $9 \pm 5 \mathrm{mins}$ to cold as compared $11 \pm 7 \mathrm{mins}$ to pinprick, $8 \pm 7 \mathrm{mins}$ to cold. The cephalad spread of sensory blocks was higher with bupivacaine( Pinprick T7 and cold T4) than with ropivacaine (Pinprick T9 and cold T6). ${ }^{[7]}$

In $\mathrm{Ph}$ E. Guatier, De Kock et al in their comparison between isobaric bupivacaine $8 \mathrm{mg}$ and intrathecal ropivacaine $8 \mathrm{mg}$, $10 \mathrm{mg}, 12 \mathrm{mg}$ and $14 \mathrm{mg}$ found the time to maximum motor block as $15 \pm 9,20 \pm 11,20 \pm 11,20 \pm 11$ and $18 \pm 13$ minutes 
respectively. There was a significant difference in the percentage of patients attaining maximum motor block between $8 \mathrm{mg}$ bupivacaine and $8 \mathrm{mg}, 12 \mathrm{mg}$ and $14 \mathrm{mg}$ ropivacine which means that ropivacaine produces less motor impairment at the same dose as bupivacaine. ${ }^{[8]}$

Helena Kallio et al in their study of plain solutions of Ropivacaine $20 \mathrm{mg}, 15 \mathrm{mg}$ and bupivacaine $10 \mathrm{mg}$ for lower limb surgeries found the median duration of complete motor block as 100, 40 and 100 minutes respectively. ${ }^{[9]}$

In comparison of $0.5 \%$ and $0.75 \%$ isobaric ropivacaine for lower limb surgeries by Van Kleef et al the onset of motor block was 8.5(2-21)mins and 6(2-21)mins and duration to achieve maximum block was 21(8.5-28.5)mins and 16(631)mins respectively. Both these were not significant. However only 535 of $0.5 \%$ ropivacaine and $90 \%$ of $0.75 \%$ ropivacaine achieved complete block. The lesser lipd solubility of ropivacaine may cause this drug to penetrate large myelinated A fibers more slowly than the more lipid bupivacaine. ${ }^{[10]}$

\section{Conclusion}

A study was conducted in 50 patients belonging to ASA grade I and II posted for lower limb surgeries. They received $3.5 \mathrm{ml}$ of $0.75 \%$ isobaric Ropivacaine in L2-3 interspace. All patients were preloaded with $1000 \mathrm{ml}$ of ringer lactate. Following institution of subarachoid block sensory characteristics such as onset of sensory block, maximum level achieved, duration of sensory block and request for first dose of rescue analgesics were studied. Motor blockade characteristics such as onset of motor block, duration and quality of motor blockade were studied.
Onset of sensory block till T10 level was found to be 8.5minutes with a complete regression in 229.28 minutes.

\section{References}

1. Akerman B,Hellberg B,Trossvik C. Primary evaluation of the local anaesthetic properties of the amino amide agent ropivacaine (LEA 103). Acta Anaesthesiol Scand 1988;32:571

2. Albright GA. Cardiac arrest following regional anesthesia with etiocaine or bupivacaine (Editorial).Anaesthesiology 1979;51:285-7.

3. Brown DL. Spinal block in Atlas of Regional Anesthesia,2nd Edition,Philadelphia, WB Saunders Company,1999

4. Pollock JE,Liu SS,Neal JM,Wylie: Dilution of spinal lidocaine does not alter the incidence of transient neurologic symptoms. Anesthesiology 1991;90:445-50.

5. Scheider M,Ettlin T,Kaufmann M,Schumacher P,Urwyler A,HamplK: Transient neurologic toxicity after hyperbaric subarachanoid anesthesia with 0.5\% lidocaine. Anesth Analg 1993;76:1154-7.

6. Jack W.van Kleef,Bernadette Th.Vering,Anton G.L.Burm.Spinal anesthesia with ropivacaine : a double-blind study on the efficacy and safety of $0.5 \%$ and $0.75 \%$ solutions in patients undergoing minor lower limb surgery. Anesth Analg 1994;78:1125-30.

7. Jean-Marc Malinovsky,Florence Charles,Ottmar Kick,Jean-Yves Lepage,Myriam Malinge,Antoine Cozian,Olivier Bouchot,Michel Pinaud. Intrathecal anesthesia: ropivacaineversus bupivacaine. Anesth Analg 2000;91:1457-60.

8. Ph. E. Gautier,M. De Kock, Van Steenberg,N. Poth,B. LahayeGoffart,L.Fanard,J . L. Hody. Intrathecal ropivacine for ambulatory surgery: a comparison between intrathecal bupivacaine and intrathecal ropivacaine for knee arthroscopy. Anesthesiology 1999;91:1239-45.

9. Helena Kallio, Eljais-Veli T. Snail, Markku P. Kero, Per H.Rosenberg. A comparison of intrathecal plain solutions containing ropivacaine 20 or $15 \mathrm{mg}$ versus bupivacaine $10 \mathrm{mg}$. Anesth Analg 2004;99:713-7.

10. Jack W.van Kleef,Bernadette Th.Vering,Anton G.L.Burm.Spinal anesthesia with ropivacaine : a double-blind study on the efficacy and safety of $0.5 \%$ and $0.75 \%$ solutions in patients undergoing minor lower limb surgery. Anesth Analg 1994;78:1125-30

Copyright: (c) the author(s), publisher. Academia Anesthesiologica International is an Official Publication of "Society for Health Care \& Research Development". It is an open-access article distributed under the terms of the Creative Commons Attribution Non-Commercial License, which permits unrestricted non-commercial use, distribution, and reproduction in any medium, provided the original work is properly cited.

How to cite this article: Saini M, Mudgal N, Engineer S.The Study was Conducted Using Isobaric 0.75\% Ropivacaine 3.5ml (26.25mg) Intrathecally for Lower Limb Surgeries to Evaluate Onset and Duration of Sensory Block \& Onset and Duration of Motor Block. Acad Anesthesiol. Int. 2019;4(2): 55-57.

DOI: dx.doi.org/10.21276/aan.2019.4.2.14

Source of Support: Nil, Conflict of Interest: None declared. 